\title{
EVALUATION OF ANTI-OBESITY ACTIVITY OF SOLASODINE IN HIGH FAT DIET-INDUCED OBESITY IN RAT
}

\author{
SATISH KHASERAO*, RAHUL SOMANI \\ Faculty of Pharmacy, Pacific Academy of Higher Education and Research University, Udaipur, Rajasthan, India \\ Email: satishkhaserao@gmail.com
}

Received: 24 Feb 2016 Revised and Accepted: 09 Jan 2017

\begin{abstract}
Objective: This study was planned to study the anti-obesity activities of solasodine on high fat (HF) diet-induced obese rats.

Methods: Wistar rats were divided into six groups. Control group (Group 1) received normal diet and $0.5 \%$ CMC (5 ml/kg). HF control group (Group 2) received HF diet. Group 3 received orlistat (25 mg/kg body weight per oral). Group 4, 5 and 6 received 25, 50 and $100 \mathrm{mg} / \mathrm{kg}$ body weight solasodine respectively. Treatment was given for $6 \mathrm{w}$ to the respective group along with HF diet. Body weight, food intake and abdomen circumference was measured every week for $6 \mathrm{w}$. On day 42, the serum biochemical parameters like blood glucose and insulin, serum leptin, total cholesterol and triglyceride were evaluated. Animals were sacrificed with overdose of diethyl ether. The liver and retroperitoneal adipose tissues were removed and weighed immediately.
\end{abstract}

Results: Treatment with solasodine at dose of $50 \mathrm{mg} / \mathrm{kg}$ and $100 \mathrm{mg} / \mathrm{kg}$ significantly $(\mathrm{p}<0.001)$ reduced body weight, abdomen circumference and retroperitoneal adipose tissue weight as compared to the $\mathrm{HF}$ diet control group. Solasodine also significantly reduced serum total cholesterol, triglyceride and glucose level as compared to HF diet control group ${ }^{* * *} \mathrm{p}<0.001,{ }^{* *} \mathrm{p}<0.01,{ }^{*} \mathrm{p}<0.05$ when compared with normal control. $\# \# \#$ p $<0.001, \# p<0.05$ when compared with high fat control). In addition, it also inhibited the induction of fatty liver with accumulation of hepatic triglyceride.

Conclusion: Solasodine exhibited anti-obesity effect by showing a reduction in body weight, abdomen circumference, total cholesterol level, triglyceride level and glucose level in high-fat diet fed rats.

Keywords: Obesity, Metabolic syndrome, Solasodine, Solanum xanthocarpum, HF diet-induced obesity

(C) 2016 The Authors. Published by Innovare Academic Sciences Pvt Ltd. This is an open access article under the CC BY license (http://creativecommons.org/licenses/by/4. 0/) DOI: http://dx.doi.org/10.22159/ijpps.2017v9i3.16025

\section{INTRODUCTION}

Metabolic syndrome, obesity and diabetes mellitus are globally increasing to the epidemic. The global impact of these disorders is immense in terms of human agony and economic burden. Atypical adipose deposition and function along with insulin resistance is important to risk factor for metabolic syndrome [1]. Obesity is one of the important components of the metabolic syndrome. Reduction in weight can enhance sensitivity to insulin and it also reduces increased levels of insulin [2]. Excessive body weight and unhealthy distribution of fat characterises obesity.

Obesity is an imbalance between energy intake and expenditure [3]. It occurs due to excessive calorie intake (HF diet), sedentary lifestyle [4]. Obesity has reached to epidemic proportions globally and is one of the important contributing factors to the global burden of chronic disease and disability. According to data reported by Yun JW and other authors $[5,6]$, more than one billion adults worldwide are overweight, and at least 300 million of them are clinically obese. Multiple factors contribute to the aetiology of obesity; it includes the sitting lifestyles, white collar jobs, lack of physical exercise and consumption of energy-rich diets. The treatment of obesity is difficult and challenging due to obscure aetiology [7]. Obesity is associated with higher incidence of serious conditions like diabetes mellitus, hypertension, dyslipidemia, cardiac alteration, lung diseases, cancer and neurological disorders and very important metabolic syndrome.

Anorectic drugs like rimonabant and sibutramine (endocannibinoid receptor antagonist) were taken out from the market due to safety concerns. Thus, the demand for the search of novel and safer antiobesity medicines is in always great demand $[8,9]$. Orlistat, the commonly used anti-obesity drug is currently available in the market. Side effects like a headache, dry mouth, constipation and insomnia are reported with orlistat. Orlistat is reported to promote weight loss to the tune of 5 to $10 \%$, but weight rebounds when its treatment is discontinued [3]. Newer antiobesity drugs are always in demand. Anti-obesity effect of new drugs can be screened using several animal models. To learn more about human obesity and about anti-obesity drugs, the rodent model of rats and mice are commonly used $[10,11]$. The animal model used to screen anti-obesity drug includes $\mathrm{HF}$ diet-induced obesity model, sulpiride-induced obesity model and cafeteria diet-induced obesity model in rats $[11,12]$.

Plants have formed the source of traditional medicine systems. Various studies with herbal medicines (including preclinical screening and clinical study) have been performed and published which has proved the significant improvement in regulating the body weight, without any obvious adverse effects and hence they are used in the management of obesity. Therefore, they have been widely used in treating obesity $[5,8,13]$. Solanum xanthocarpum fruits are known for several traditional uses as medicine, like anthelmintic, laxative, antipyretic, anti-asthmatic, anti-inflammatory activity and enlargement of liver [14-16].

Pharmacological effects like hypoglycaemic [17], hepatoprotective $[13,18]$ and hypotensive activity of Solanum xanthocarpum was also reported [19]. Previous studies have reported that the major components may be responsible for prevention of obesity $[15,20]$. Antioxidant effects of solasodine, an active component of this plant is also reported [21]. There are no pharmacological studies so far reported the antiobesity potential for solasodine (isolated from Solanum xanthocarpum) to date. The promising preliminary results reported with the use of Solanum xanthocaropum in disease components of metabolic syndrome (like hypoglycaemic and antihypertensive) have prompted us to investigate the effect of isolated solasodine in rats with $\mathrm{HF}$ diet-induced obesity model, which is an important contributor to the metabolic syndrome. 


\section{MATERIALS AND METHODS}

Wistar rats of both sexes weighing between 150-180 g were obtained and kept individually in polypropylene cages in an environmentally controlled room of the animal house and maintained at a temperature of $25 \pm 2{ }^{\circ} \mathrm{C}$ with a $12 \mathrm{~h}$ dark/light cycle. The animals had free access to food and water. Rats were fed with standard rat chow diet or special high fructose diet according to the protocol. Experiments were carried out after a week of acclimatization. The animal studies were approved by the Institutional Animal Ethics Committee (IAEC/CPD/415/05), constituted for the purpose of control and supervision of experimental animals by Ministry of Environment and Forests, Government of India, New Delhi, India. Animals were naive to drug treatments and experimentation at the beginning of all studies. All tests were conducted between 08:00 and 14:00 h.

\section{Drugs}

Dried and matured fruits of Solanum xanthocarpum were collected from Surat, Gujarat (Authentification no.:Authen./03/2014). Solasodine was isolated from dried, ripen fruits of Solanum xanthocarpum Schrad. and Wendl with a method described by Gawande A et al. [22]. All other agents used were of analytical grade. The doses were selected as solasodine $(25,50,100 \mathrm{mg} / \mathrm{kg}$, per oral on the basis of previous reports and dose-finding study performed in this work [23].

\section{Antiobesity study}

The antiobesity study done and published earlier was used as a reference for evaluation of antiobesity of solasodine in this study $[8,13,24]$. Wistar rats, $4-5 \mathrm{w}$ old $(150-180 \mathrm{~g})$ were selected for the experiment. Rats were allowed to acclimatize to the experimental room conditions for a period of six days. A day before treatment, rats were randomised into six groups like normal control group (Group 1), HF diet treated control group (Group 2), treatment groups (Group 3, Group 4,Group 5 and Group 6).

Freshly prepared HF diet was used for $6 \mathrm{w}$. HF diet was given to animals for $6 \mathrm{w}$ except for normal control group (Group 1). Rats from group 4, group 5 and group 6 were administered $25 \mathrm{mg} / \mathrm{kg}$ (low dose), $50 \mathrm{mg} / \mathrm{kg}$ (medium dose) and $100 \mathrm{mg} / \mathrm{kg}$ (high dose) body weight of solasodine orally daily for $6 \mathrm{w}$. Rats from group 3 were administered orlistat ( $25 \mathrm{mg} / \mathrm{kg}$ body weight) orally daily for $6 \mathrm{w}$.

On day 42, animals were light anaesthetized, and blood was collected by retro-orbital puncture by glass capillary. After that animal were sacrificed with an overdose of ether and examined grossly. Livers were isolated from each group of animals, weighed immediately and liver tissues were embedded in paraffin for histopathology study.

Solasodine and orlistat were administered followed by administration of HF diet after a gap of $2 \mathrm{~h}$ daily for $6 \mathrm{w}$.

\begin{tabular}{ll}
\hline Group 1 & $\begin{array}{l}\text { Normal control group on laboratory pellet chow (calorie value = 3145 kcal } / \mathrm{kg}) \text { and } 0.5 \% \text { CMC } \\
\text { (carboxy methyl cellulose, } 5 \mathrm{ml} / \mathrm{kg} / \text { day by oral route) }\end{array}$ \\
Group 2 & HF diet treated control group on HF diet in addition to normal diet for $42 \mathrm{~d}$ \\
Group 3 & HF diet with normal diet+orlistat $(25 \mathrm{mg} / \mathrm{kg}$, body weight $/$ day by oral route) \\
Group 4 & HF diet with normal diet+solasodine $(25 \mathrm{mg} / \mathrm{kg}$, body weight $/$ day by oral route) \\
Group 5 & HF diet with normal diet+solasodine $(50 \mathrm{mg} / \mathrm{kg}$, body weight $/$ day by oral route) \\
Group 6 & HF diet with normal diet+solasodine $(100 \mathrm{mg} / \mathrm{kg}$, body weight/day by oral route)
\end{tabular}

\section{Clinical signs}

After dosing, all animals were observed for tremor, convulsion, aggression, lethargy, abdominal breathing, grooming, licking and sniffing.

\section{Body weight}

Body weight (g) of the study animals in each group was recorded on day 1 and then every $6 \mathrm{w}$.

\section{Food intake}

The process of measurement of solid food consumption was done by weighing the different food items deposited in each cage each day, and determining the weights of the food remaining the day after. These needed some corrections, as part of the food was tainted with droppings and urine. The identifiable pieces of food were cleaned and their actual weight was determined. The food intake of each animal was determined daily and the results were expressed as a mean energy intake for each group of rats in kilocalorie per week (kcal/week).

$$
\begin{aligned}
\text { Total energy intake } & \left(\frac{\mathrm{kcal}}{\text { week }}\right) \\
& =\text { Mean food consumption X Calorie from chow }
\end{aligned}
$$

\section{Measurement of abdominal circumference}

The abdominal circumference (immediately anterior to the forefoot) was determined in all rats weekly for $6 \mathrm{w}$.

\section{Biochemical parameters}

On day 42 , blood was collected by retro-orbital punctures by glass capillary under light anaesthesia. Blood was kept for 30 min for coagulation and then serum was separated by centrifugation at 4000 rpm (revolutions per minute). Changes in blood parameters like levels of glucose, total cholesterol and triglyceride were measured from serum samples using biochemical kits available in the market (End-point otoluidine method for glucose, J. Mitra and Co. Ltd.; One step method of Wybenga and Pilleggi for total cholesterol, Span diagnostics; enzymatic method, GPO/Trinder, end point colorimetry for triglycerides, Span diagnostics, Surat, India).

Serum insulin levels [25], serum leptin levels [26], advanced glycosylated end product [27], oxidative stress markers [28, 29], HOMA-IR (homeostatic model assessment and insulin resistance) [30] and AST (aspartate aminotransferase) and ALT (alanine aminotransferase) levels were estimated as per procedure described earlier by respective authors and with help of standard kits available in the market.

\section{Determination of retroperitoneal adipose tissue mass}

On day 42, after blood collection by retro-orbital, animals were sacrificed with an overdose of ether. Triangular area of retroperitoneal fat was removed from each side. The triangle was always dissected with the vertex in the inguinal region, the base of the lower pole of the kidney, one side with the midline and the other sides extending over the lateral retroperitoneal reaches as far as fat was visible. The tissues were washed free of adherent oil droplets with warm, isotonic saline, placed on a tared, butter paper and weighed to provide a measure of wet weight.

\section{Estimation of liver weight}

On day 42 , animals were sacrificed with an overdose of ether. Livers were quickly removed and weighed using analytical balance.

\section{Liver histopathology}

For histopathological studies, a small portion of the liver tissue from all groups of animals was excised immediately after sacrifice. Liver tissues were fixed in $10 \%$ formalin for $24 \mathrm{~h}$ at room temperature. Liver tissues were embedded in paraffin and sections were cut 3-5 $\mu \mathrm{m}$ slides and were stained with haematoxylin and eosin. Liver tissues were observed under the microscope.

\section{Statistical analysis}

Results were expressed as mean (s) \pm SEM (standard error of the mean). The statistical significance of the difference between groups 
for the various treatments was determined by one-way analysis of variance (ANOVA) followed by Tukey's multiple range test. The probability value $\mathrm{p}<0.05$ was considered statistically significant as compared to control.

\section{RESULTS}

\section{Clinical signs}

All groups were treated with solasodine for $6 \mathrm{w}$. immediately after dosing, rats removed husk by forepaw and sat on a husk free space for $30 \mathrm{~min}$. This was observed in all solasodine treated groups. No clinical signs like tremors, convulsions, piloerection were observed.

\section{Effect of solasodine on food intake (calorie intake)}

There was a significant $(p<0.05)$ increase in calorie intake per week among the HF diet-fed rats as compared to the normal diet-fed rats. However, the rats treated with orlistat showed a less significant $(p<0.05)$ decrease in calorie intake per week. But rats treated with solasodine showed a significant effect in food intake (fig. 1).

\section{Effect of solasodine on body weight}

Consumption of HF produced a significantly increased in body weight as compared to the consumption of normal diet (normal control group) after $1 \mathrm{w}$ of treatment and continued up to $6 \mathrm{w}$. Treatment with solasodine at a dose of 25,50 and $100 \mathrm{mg} / \mathrm{kg}$ body weight significantly reduced body weight as compared to the HF control group. After $4 \mathrm{w}$, solasodine at a dose of $50 \mathrm{mg} / \mathrm{kg}$ and after $3 \mathrm{w}$ solasodine at a dose of $100 \mathrm{mg} / \mathrm{kg}$ showed significant $(\mathrm{p}<0.001)$ reduction in body weight as compared to HF control group. However, treatment with orlistat also reduced body weight, significantly $(\mathrm{p}<0.001)$ as compared to HF control group. (fig. 2)

\section{Effect of solasodine on abdomen circumference}

Significant change in abdomen circumference was showed in rats fed with HF diet as compared to normal control. Solasodine at a dose level of $50 \mathrm{mg} / \mathrm{kg}$ and $100 \mathrm{mg} / \mathrm{kg}$ showed statistically significant $(13.85 \pm 0.18$ and $13.78 \pm 0.24$ respectively) reduction in abdomen circumference as compared to HF control group (19.28 \pm 0.22$)$ and normal control group $(15.06 \pm 0.14)$. Orlistat also showed significant $(15.06 \pm 0.11)$ reduction in abdomen circumference as compared to HF control group (table 1).

\section{Effect of solasodine on serum biochemical parameters and blood pressure}

Feeding of HF diet caused a significant $(\mathrm{p}<0.001)$ increase in serum levels of total cholesterol, triglycerides and glucose as compared to normal diet fed rats at the end of study (Day 40).

In contrast, further solasodine at 25, 50 and $100 \mathrm{mg} / \mathrm{kg}$ dose and orlistat significantly $(\mathrm{p}<0.05$ and $\mathrm{p}<0.001)$ reduced total cholesterol level as compared to HF control group. Solasodine treated group also showed significant $(\mathrm{p}<0.001)$ increase in total cholesterol level as compared to normal control.

Solasodine $(25,50$ and $100 \mathrm{mg} / \mathrm{kg}$ ) and orlistat-treated group on day 40 showed significant $(\mathrm{p}<0.001)$ reduction in triglyceride level as compared to HF control group.
Glucose level was significantly $(\mathrm{p}<0.01)$ decreased by solasodine at all dose level as compared to HF control group. Rats treated with orlistat at $25 \mathrm{mg} / \mathrm{kg}$ showed significant $(\mathrm{p}<0.001)$ increase in glucose level as compared to normal control (fig. 3).

The increase in plasma insulin level and HOMA-IR in HF control group was significantly $(\mathrm{p}<0.001)$ reduced by standard drug and test drug at all dose levels. Similar results were also found with advanced glycated end products.

After $42 \mathrm{~d}$ of HF diet blood pressure rose by $30 \%$ which was significantly $(\mathrm{p}<0.05)$ reduced by orlistat and solasodine treated groups (fig. 3 ).

\section{Effect on liver enzymes and oxidative stress parameters}

The free radical scavenging enzyme, SOD (superoxide dismutase), catalase and GSH (glutathione) activity in serum was reduced significantly in $\mathrm{HF}$ rat compared to normal rats. Solasodine treatment significantly enhanced levels of the antioxidant enzyme in treated group of rats (fig. 4). The ALT and AST levels were significantly increased in HF control group which was significantly decreased in solasodine treated groups. The effect on ALT and AST was more in high dose as compare to low dose solasodine.

Effect of solasodine on retroperitoneal adipose tissue weight and liver weight

Feeding a HF diet for six weeks produced significant $(\mathrm{p}<0.001)$ increase in weight of retroperitoneal adipose tissue as compared to retroperitoneal adipose tissue in normal diet fed rats (fig. 5). Treatment with solasodine significantly $(\mathrm{p}<0.01$ and $\mathrm{p}<0.001)$ reduced the weight of retroperitoneal adipose tissue in a dosedependent manner as compared to the HF control group. Rats those were treated with orlistat also showed significant $(p<0.05)$ reduction in the weight of retroperitoneal adipose tissue as compared to HF control group.

Rats treated with solasodine showed significant $(\mathrm{p}<0.01)$ reduction in liver weight as compared to HF control group. Furthermore, the $\mathrm{HF}$ diet al. so induced fatty liver, with an accumulation of triglycerides when compared to the normal control group.

\section{Effect of solasodine on histopathology of rat liver}

The section from liver showed that the central veins, portal triads surrounded by cords of normal looking hepatocytes. Congestion, macrovesicular fatty changes, necrosis and inflammation, were not present in normal rat liver (fig. 6A). Histopathology of the liver in rats fed on HF diet showed focal distortion of the normal architecture of liver, focal areas of inflammatory cells infiltration, macrovesicular fatty changes and focal areas of necrosis (fig. 6B). Rats those were treated with orlistat along with HF diet showed loss of architecture, inflammation, congestion, sinusoidal dilation and necrosis. It also showed fatty changes (fig. 6C). Liver section of rats treated with solasodine $(50 \mathrm{mg} / \mathrm{kg})$ along with HF diet showed mild congestion focal, macrovesicular fatty changes, mild kupfer cells proliferations and focal infiltration of inflammatory cells. However, it was not extensive in compared to HF diet control group (fig. 6D). Liver section from rats treated with solasodine $(100 \mathrm{mg} / \mathrm{kg})$ in addition to HF diet showed regeneration of hepatocytes toward normal architecture compared to HF diet control group (fig. 6E).

Table 1: Effect of solasodine on abdomen circumference (cm) in rats fed on high fat (HF) diet

\begin{tabular}{llllll}
\hline Week & $\begin{array}{l}\text { Normal } \\
\text { control }\end{array}$ & $\begin{array}{l}\text { High fat } \\
\text { control }\end{array}$ & $\begin{array}{l}\text { High fat+Orlistat } \\
\mathbf{( 2 5} \mathbf{~ m g} / \mathbf{k g})\end{array}$ & $\begin{array}{l}\text { High fat+Solasodine } \\
\mathbf{( 2 5} \mathbf{~ m g} / \mathbf{k g})\end{array}$ & $\begin{array}{l}\text { High fat+Solasodine } \\
\mathbf{5 0} \mathbf{~ m g} / \mathbf{k g})\end{array}$ \\
\hline 0 & $13.58 \pm 0.20$ & $13.58 \pm 0.24$ & $14.73 \pm 0.87$ & $13.88 \pm 0.22$ & $\begin{array}{l}\text { High fat+Solasodine } \\
\mathbf{( 1 0 0} \mathbf{~ m g} / \mathbf{k g})\end{array}$ \\
1 & $14.21 \pm 0.27$ & $15.03 \pm 0.26$ & $14.09 \pm 0.64^{\#}$ & $13.96 \pm 0.23$ \\
2 & $14.73 \pm 0.20$ & $15.95 \pm 0.16^{* *}$ & $14.29 \pm 0.24^{\# \# \#}$ & $14.08 \pm 0.19^{\# \# \#}$ & $13.86 \pm 0.37$ \\
3 & $14.86 \pm 0.22$ & $15.71 \pm 0.16^{*}$ & $14.46 \pm 0.18^{\# \# \#}$ & $14.26 \pm 0.14^{\# \# \#}$ & $13.65 \pm 0.15^{\#}$ \\
4 & $15.06 \pm 0.27$ & $16.66 \pm 0.26^{* * *}$ & $14.50 \pm 0.09^{\# \# \#}$ & $14.45 \pm 0.11^{\# \# \# \#}$ & $13.88 \pm 0.21^{\# \# \#}$ \\
5 & $15.18 \pm 0.21$ & $18.51 \pm 0.22^{* * *}$ & $14.89 \pm 0.18^{\# \# \#}$ & $14.8 \pm 0.04^{\# \# \#}$ & $13.81 \pm 0.16^{\# \# \#}$ \\
6 & $15.06 \pm 0.14$ & $19.28 \pm 0.22^{* * *}$ & $15.06 \pm 0.11^{\# \# \#}$ & $15.06 \pm 0.06^{\# \# \#}$ & $14.03 \pm 0.18^{* * \# \# \#}$ \\
\hline
\end{tabular}

Values are expressed as mean \pm SEM Data were analyzed by one-way analysis of variance (ANOVA) followed by Tukey's test $(\mathrm{n}=6)$. ${ }^{* * *} \mathrm{p}<0.001$, ${ }^{* *} \mathrm{p}<0.01,{ }^{*} \mathrm{p}<0.05$ when compared with normal control. \#\#\#<<0.001, ${ }^{\#} \mathrm{p}<0.05$ when compared with high fat control. 


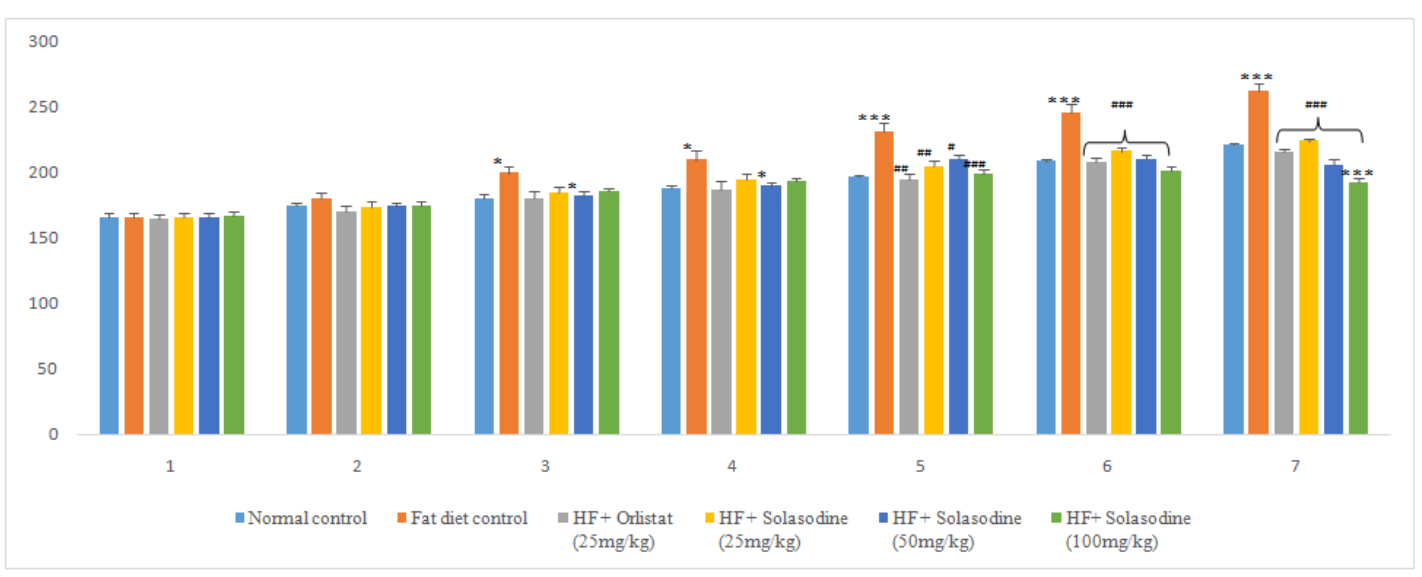

Fig. 1: Effect of solasodine on calorie intake (kcal/week) for rats fed on high-fat (HF) diet

Values are expressed as mean \pm SEM Data were analyzed by one-way analysis of variance (ANOVA) followed by Tukey's test ( $\mathrm{n}=6$ ). ${ }^{*} \mathrm{p}<0.05$ when compared with normal control, 1=Week '0'; 2=Week '1'; 3=Week '2'; 4=Week '3'; 5=Week '4'; 6=Week '5'; 7=Week '6'.

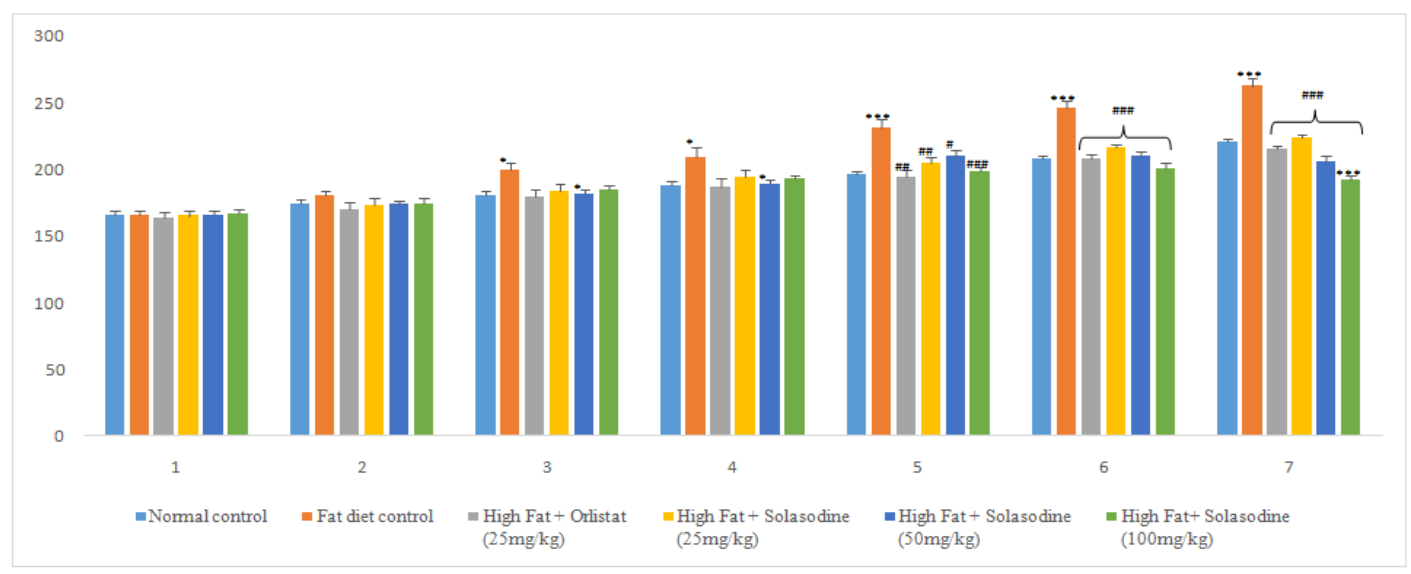

Fig. 2: Effect of solasodine on body weight (g) in rats fed on high-fat (HF) diet

Values are expressed as mean \pm SEM Data were analysed by one-way analysis of variance (ANOVA) followed by Tukey's test $(\mathrm{n}=6) .{ }^{* * *} \mathrm{p}<0.001$,

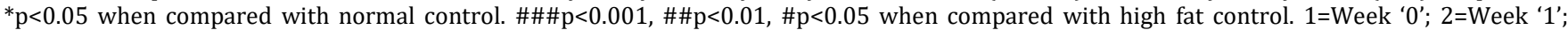
$3=$ Week '2'; 4=Week '3'; 5=Week '4'; 6=Week '5'; 7=Week '6'.

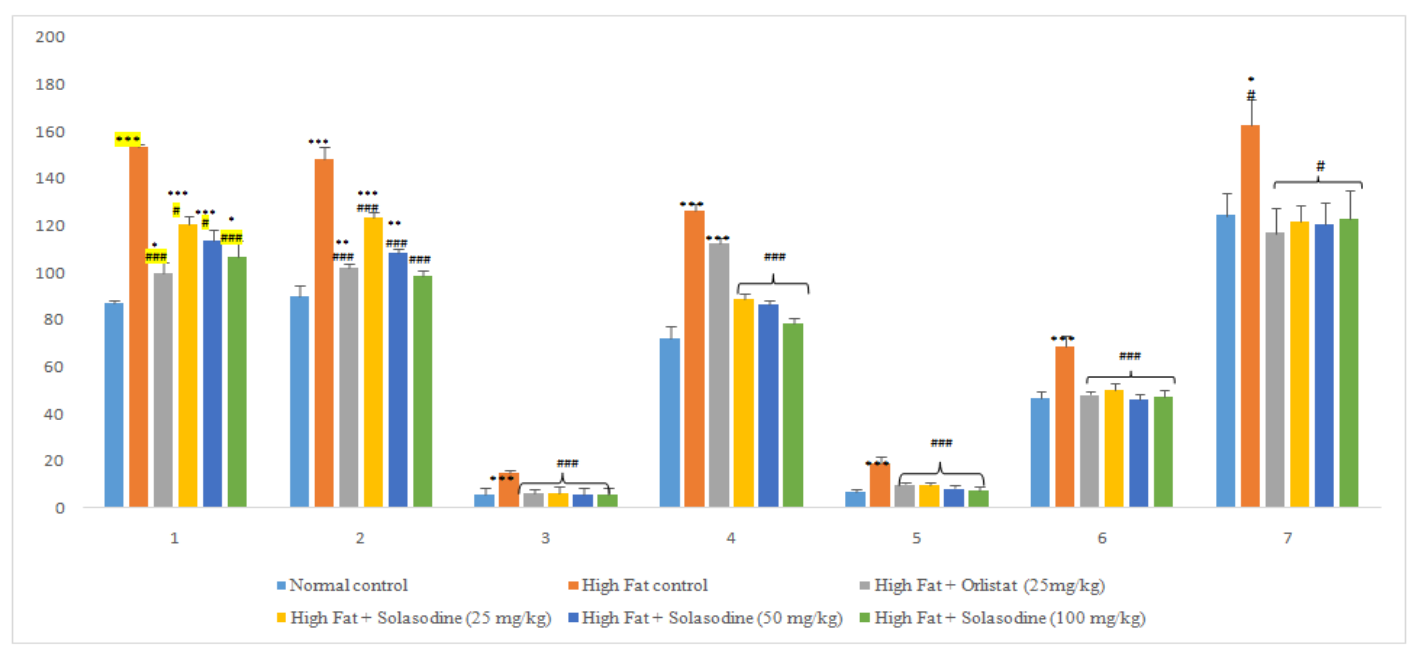

Fig. 3: Effect of solasodine on serum biochemical parameters in rats fed on high-fat (HF) diet

Values are expressed as mean \pm SEM Data were analyzed by one way analysis of variance followed by Tukey's test $(\mathrm{n}=6) .{ }^{* * *} \mathrm{p}<0.001,{ }^{* *} \mathrm{p}<0.01$, ${ }^{*} \mathrm{p}<0.05$ when compared with normal control, \#\#\#p<0.001, \#p<0.05 when compared with high fat control, $1=$ Total cholesterol (mg/dl); $2=$ Triglyceride $(\mathrm{mg} / \mathrm{dl}) ; 3=$ Serum leptin $(\mathrm{ng} / \mathrm{ml}) ; 4=$ Glucose $(\mathrm{mg} / \mathrm{dl}) ; 5=$ Plasma insulin $(\mu \mathrm{U} / \mathrm{ml}) ; 6=$ AGEs [(advanced glycated end products) (pg/mg protein)]; $7=$ Systolic blood pressure $(\mathrm{mmHg})$. 


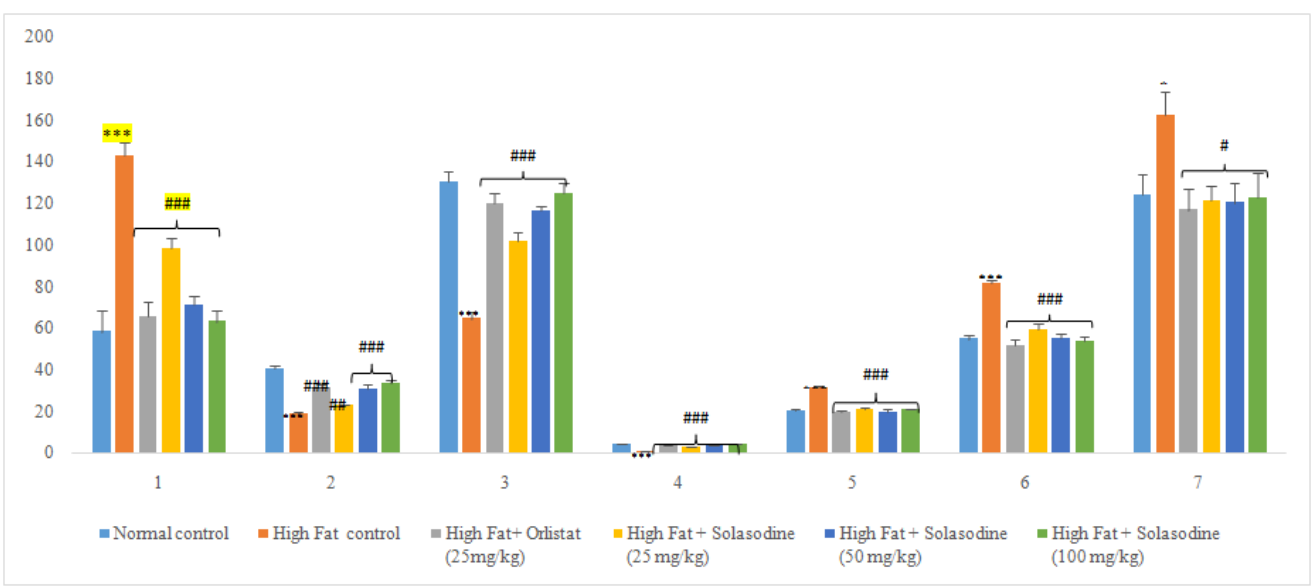

Fig. 4: Effect of solasodine on the liver enzymes and oxidative stress parameters in rats fed on high-fat (HF) diet

Value are expressed as mean \pm SEM Data were analyzed by one way analysis of variance followed by Tukey's test $(n=6) . * * * p<0.001$, ${ }^{* *} \mathrm{p}<0.01,{ }^{*} \mathrm{p}<0.05$ when compared with normal control. \#\#\#p<0.001, \#p<0.05 when compared with high fat control

1=Hepatic TBARS (thiobarbituric acid reactive substances) level (nmol/g wet tissue); 2=Hepatic GSH (glutathione) level (mg/g wet tissue); 3=Hepatic SOD (superoxide dismutase) activity (U/mg protein); 4=Hepatic catalase activity (U/mg protein); $5=$ ALT (alanine transaminase) (U/l); $6=$ AST (aspartate transaminase) (U/l); 7=Systolic blood pressure ( $\mathrm{mmHg}$ ).

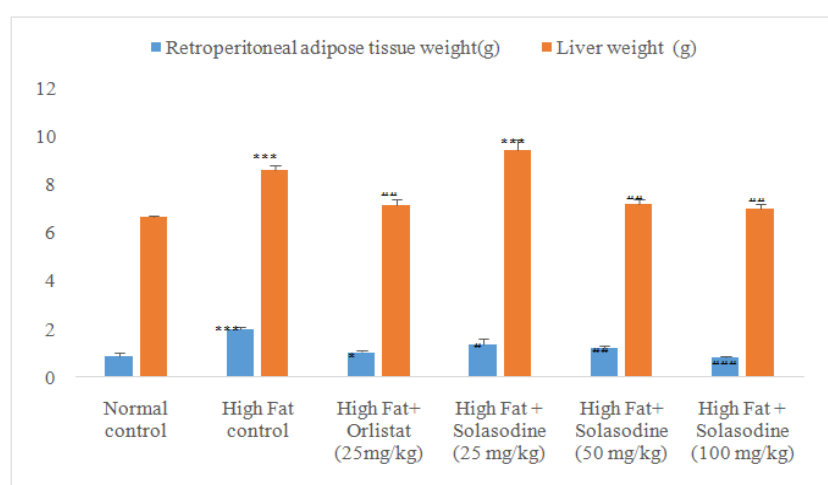

Fig. 5: Effect of solasodine on the retroperitoneal adipose tissue weight and liver weight in rats fed on high-fat (HF) diet

Value are expressed as mean \pm SEM Data were analysed by one-way analysis of variance followed by Tukey's test $(\mathrm{n}=6),{ }^{* * *} \mathrm{p}<0.001$ when

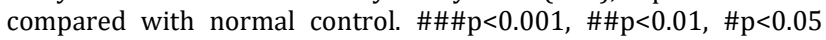
when compared with high fat control.

In Fig. 6 A: Normal control showing central veins, portal triads surrounded by cords of normal looking hepatocytes; B: High-fat (HF) diet control showing inflammatory cells infiltration, macrovesicular fatty changes and focal areas of necrosis; C: Orlistat+high fat diet showing fatty changes; D: Solasodine $(50 \mathrm{mg} / \mathrm{kg})+$ high fat diet mild congestion less severe than high fat control group (B); E: Solasodine $(100 \mathrm{mg} / \mathrm{kg})+$ high fat diet showing normal architecture compared to HF diet control group.

\section{DISCUSSION}

Newer and the most important safer antiobesity drugs are always in demand [8]. In the light of the ban on endocannibinoid receptor antagonists like rimonabant and sibutramine (anorectic drug) and side effects of antiobesity drug orlistat, the need of safer drugs is always there [9].

As stated earlier plant and herbs are the foundation of the traditional system. Plants have shown considerable improvement in parameters of obesity devoid of any visible adverse effects. Hence, they are being widely used in treating obesity [5].
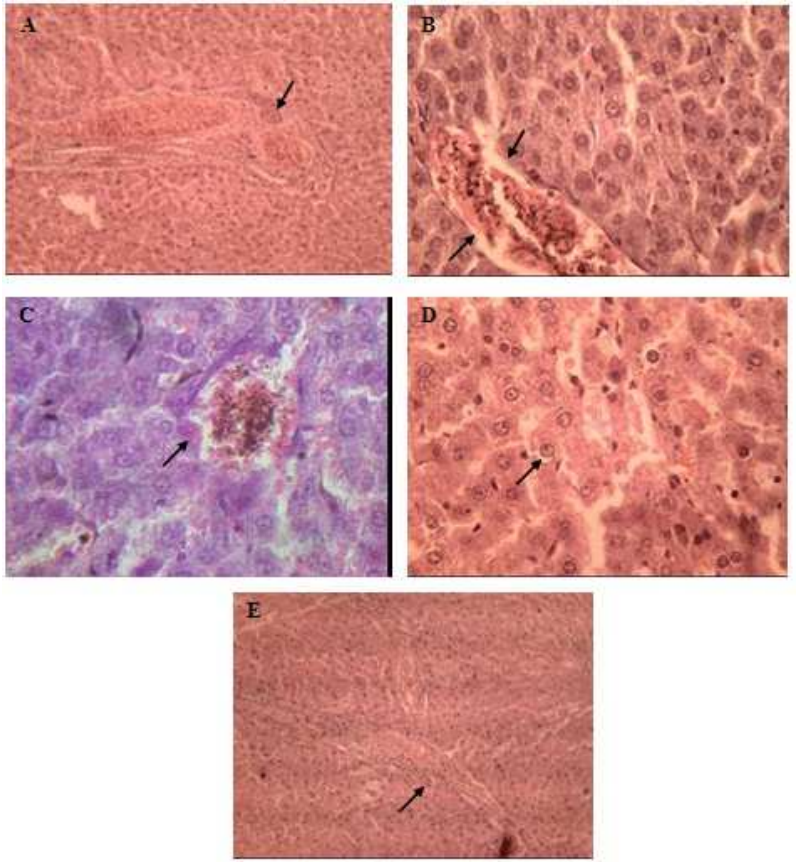

Fig. 6: Effect of solasodine on histopathology of liver in rats fed on high-fat (HF) diet

In order to find effective antiobesity treatments, different animal models of obesity have been used. Rat models with HF-induced obesity, cafeteria diet-induced obesity are considered useful for evaluation of the antiobesity effect of drugs. The supplementation of $\mathrm{HF}$ in their diet is an imperative factor which leads to the development of obesity.

The current study was conducted by using HF diet-induced obesity model in rats. HF diets have been previously reported to increase energy intake and cause obesity in humans as well as animals (11, 12). The following parameters were used for antiobesity assessment of solasodine. It includes the effect on body weight, abdomen circumference, food intake, total cholesterol measurement, triglyceride and glucose level measurement retroperitoneal adipose 
tissue weight, liver weight and histopathology of the liver. It is known that obesity results from an imbalance between energy intake and expenditure [31]. Further, the composition and variety of cafeteria or high-fat foods also exert a synergistic effect on the development of obesity. The results of the present study showed that rats fed with HF which is rich in energy and high carbohydrate for six weeks elicited a significant increase in body weights. HF control group showed a significant increase in food intake as compared to normal control group. Animals treated with solasodine have shown a significant effect on parameters of obesity as compared to HF control group. Treatment with solasodine at a dose of 25,50 and $100 \mathrm{mg} / \mathrm{kg} /$ day, significantly reduced the increase in body weight and other biomarkers of obesity induced by a HF diet is a clear sign of the antiobesity effect.

A clinical sign like grooming was observed immediately after dosing. This may be due to irritant effect of solasodine. Animals removed husk by forepaw and sat on a husk free place, it was observed for 30 min immediately after dosing of solasodine. This may be due to some CNS (central nervous system) effect of solasodine in rats. Also sniffing was observed in rats which may be due to the smell of solasodine and its bronchodilator activity.

A lipase inhibitor which reduces the fat digestion and thereby its absorption is one of the commonly accepted approaches in decreasing calorie intake. Pancreatic lipase hydrolyzes fats into fatty acid and monoacylglycerols. These are the absorbable forms of fats. Hence, inhibiting of pancreatic lipase may result in stopping hydrolysis of fat into absorbable fat units. Orlistat, an approved antiobesity drug currently marketed. It prevents obesity and hyperlipidaemia by increasing fat excretion in faeces and by inhibiting the pancreatic lipase [8]. The solasodine significantly reduced abdomen circumference as compared to HF control group. The reduction in body weight corresponded with that of reduction in abdomen circumference. In obese animals and humans, it is seen that there is an increase in levels of serum lipids (for e. g. total cholesterol and triglycerides). Thus, alteration in the levels of lipid can be used as an index of obesity. It is known that the high lipid content (hyperlipidaemia) leads to many life-threatening conditions such as heart disease, stroke and other vascular diseases [7]. A decrease in calorie intake, especially from fat consumption, is one of the essential steps in the treatment of obesity. Obesity is also the most common cause of dyslipidaemia. The excess lipid supply in a state of obesity leads to higher triglyceride stores in non-adipose tissues e. g. muscle, liver and pancreas [32]. Treatment with solasodine has caused significant changes in the blood parameters like decreased levels of lipids like total cholesterol, triglyceride and carbohydrate like glucose. The results of the present study showed that rats fed with HF foods for six weeks produced a significant increase in weight of retroperitoneal adipose tissue and serum lipid levels. Furthermore, HF diet al. so induced a fatty liver with the build-up of hepatic triglycerides [8]. The solasodine produced a significant decrease in liver weight and the retroperitoneal adipose tissue weight as compared to the HF diet control group. The rate of reduction of body weight was similar to that in the retroperitoneal adipose tissue weight.

The microscopical examination of a liver section of HF diet treated group showed various degrees of pathological changes such as fatty degeneration cloudy swelling and necrosis of hepatic cells. The abnormal reconstructions of the lobular architecture, the appearance of widespread fibrosis, in addition, nodular lesions of the hepatic parenchyma are the main characteristics of liver cirrhosis [33]. The histopathology study showed that rats treated with orlistat along with HF diet showed cirrhosis like condition presenting toxic symptoms on continuous administration of orlistat. The histopathology study showed that solasodine attenuated the hepatocellular necrosis and led to a reduction in inflammatory cells infiltration. Solasodine treated group showed recovery of damaged liver cells. Earlier various authors have reported that the saponins showed strong inhibitory effects on the lipase secreted from the pancreas in vitro and prevented an increase in body weight which was induced by HF diet in vivo [34-36]. Yen et al. [37] reported that $500 \mathrm{mg} / \mathrm{kg}$ dehydroepiandrosterone administered three times weekly to mice resulted in decreased weight gain by obese mice without affecting their food intake, they also showed an inhibitory effect of the steroid on fatty acid synthesis. Thus, solasodine (a saponin) might be responsible for the reduction in weight gain as compared to animals in HF control group.

\section{CONCLUSION}

The present study was conducted to assess the antiobesity effect of solasodine isolated from dried and ripen fruits of plant Solanum xanthocarpum. Solasodine, the active component isolated from this plant showed marked antiobesity effect in rats fed on HF diet in a dose-dependent manner. Solasodine leads to decrease in body weight, abdominal circumference, lipid profile, fat deposition indicating the antiobesity potential of this component equipotent to orlistat without any toxic effect on the liver in HF-fed rats. Antiobesity effect of solasodine can be seen through the inhibition of intestinal absorption of dietary fat, blocking the fat accumulation and synthesis of fat and its hypolipidemic activity. The present study confirms the basis for the use of this plant (solasodine) in the traditional medicine for treatment of obesity. In future, this work can be extended by including more obesity models to confirm the antiobesity potential of solasodine for the meaningful and tangible conclusion.

\section{ACKNOWLEDGMENT}

Authors gratefully acknowledge Dr. Indrajeet Singhvi, Dean, Faculty of Pharmacy, Pacific University, Udaipur, Rajasthan.

\section{CONFLICT OF INTERESTS}

On behalf of all authors, the corresponding author states that there is no conflict of interest.

\section{REFERENCES}

1. Alberti KG, Zimmet P, Shaw J. The metabolic syndrome-a new worldwide definition. Lancet 2005;366:1059-62.

2. Alisi A, Manco M, Panera N, Nobili V. Association between type two diabetes and non-alcoholic fatty liver disease in youth. Ann Hepatol 2009;8(Suppl 1):S44-50.

3. Dipiro JT, Talbert RL, Yee GC, Matzke GR, Wells BG, Posey ML. Pharmacotherapy: A Pathophysiologic Approach. 6th Edn. The McGraw-Hill Companies, New York; 2005. p. 2662-70.

4. Palatty PL, Saldanha E. Pharmacotherapy for weight management. J Assoc Physicians India 2012;60:34-5.

5. Yun JW. Possible anti-obesity therapeutics from nature-a review. Phytochem 2010;71:1625-6.

6. Anitha M, Roselin ME, Monisha DM, Chella Karthik J. Prevalence of obesity and overweight among medicos in both male and female Students. Asian J Pharm Clin 2016;9:289-91.

7. Kaur G, Kulkarni SK. Antiobesity effect of a polyherbal formulation, OB-200G in female rats fed on cafeteria and atherogenic diets. Indian J Pharmacol 2000;32:294-8.

8. Kumar S, Alagwadi KR, Rao MR. Effect of Argyreia speciosa root extract on cafeteria diet-induced obesity in rats. Indian J Pharmacol 2012;43:163-6.

9. Thacker T. Slimming drug sibutramine banned in India; 2010. Available from: http://archive.indianexpress.com/ news/ slimming-drug-sibutramine-banned-in-india/710526/ [Last accessed on 01 Oct 2016].

10. Lim DW, Song Mi Kyung, Park Juyeon, Park SW, Kim NH, Gaire BP, et al. Anti-obesity effect of HT048, a herbal combination, in high fat diet-induced obese rats. Molecules 2012;17:14765-7.

11. Arcari DP, Bartchewsky W. Antiobesity effects of Yerba mate extract (Ilex paraguariensis) in high-fat diet-induced obese mice. Obesity 2009;17:2127-33.

12. Prats E, Monfar M, Castella J. Energy intake of rats fed a cafeteria diet. Physiol Behavior 1989;45:263-72.

13. Dhingra D, Jindal V, Sharma S. Evaluation of antiobesity activity of Tinospora cordifolia stems in rats. Int J Res Ayurveda Pharm 2011;2:306-11.

14. Hussain T, Gupta RK, Khan MS. Evaluation of the antihepatotoxic potential of Solanum xanthocarpum fruit extract against antitubercular drugs induced hepatopathy in experimental rodents. Asian Pac J Trop Biomed 2012;1:1-6. 
15. Balachandran P, Govindaraja R. Cancer an ayurvedic perspective. Pharmacol Res 2005;51:19-30.

16. Rasheeduz Z, Parisa H. Quantification of solasodine in callus and suspension cultures of Solanum xanthocarpum Schrad and Wendl by RP-HPLC. Int J Pharm Phytochem Res 2015;7:206-14

17. Kar DM, Maharana L, Dash GK. Studies on the hypoglycemic activity of Solanum xanthocarpum Schrad and Wendl fruit extract in rats. J Ethnopharmacol 2006;108:251-6.

18. Girish C, Koner BC. Hepatoprotective activity of six polyherbal formulations in paracetamol-induced liver toxicity in mice. Indian J Med Res 2009;129:569-78.

19. Parmar S, Gangwal A, Sheth N. Solanum xanthocarpum (Yellowberried nightshade): a review. Der Pharm Lett 2010;2:373-83.

20. Rao MM, Kandale A, Sharma K, Singh U. Evaluation of phytochemical and standardisation parameters of Solanum xanthocarpum Schrad and Wendl. Int J Chem Anal Sci 2010;1:47-9.

21. Sharma T, Airao V, Panara N, Vaishnav D, Ranpariya V, Sheth N, et al. Solasodine protects rat brain against ischemia/reperfusion injury through its antioxidant activity. Eur J Pharmacol 2014;725:40-6.

22. Gawande A, Wankhade S, Shankhopal KV, Shinde GB. Isolation, purification and characterization of solasodine-A steroidal alkaloid from Solanum surattense berries. Indian Drugs 1991;28:149-50.

23. Chauhan K, Sheth N, Ranpariya V, Parmar S. Anticonvulsant activity of solasodine isolated from Solanum sisymbriifolium fruits in rodents. Pharm Biol 2011;49:194-9.

24. Athesh K, Divakar M, Brindha P. Anti-obesity potential of Cyperus rotundus. aqueous tuber extract in rats fed on high-fat cafeteria diet. Asian J Pharm Clin Res 2014;7:88-92.

25. Mahmoud AAA, Elshazly SM. Ursodeoxycholic acid ameliorates fructose-induced metabolic syndrome in rats. PLoS One 2014;9:e106993.

26. Considine $\mathrm{R}$, Sinha $\mathrm{M}$, Serum immunoreactive leptin concentrates in normal weight and obese human. N Engl J Med 1996;334:292-5.
27. Sampathkumar R, Balasubramanyam M, Rema M, Premanand C, Mohan V. A novel advanced glycation index and its association with diabetes and microangiopathy. Metab Clin Exp 2005;54:1002-7.

28. Kakkar P, Das B, Viswanathan PN. A modified spectrophotometric assay of superoxide dismutase. Indian J Biochem Biophys 1984;21:130-2.

29. Ellman GL. Tissue sulfhydryl groups. Arch Biochem Biophys 1959;82:70-7.

30. Matthews DR, Hosker JP, Rudenski AS, Naylor BA, Treacher DF. Homoeostasis model assessment: insulin resistance and betacell function from fasting plasma glucose and insulin concentrations in man. Diabetologia 1985;28:412-9.

31. Gupta S, Kaushik M. Histomorphological and hypolipidaemic effects from the whole plant of Gymenma sylvestre in high cafeteria diet-induced obese rat model. J Pharm Biomed Sci 2010;2:1-9.

32. Castejon MG, Casado AR. Dietary phytochemicals and their potential effects on obesity: a review. Pharmacol Res 2011;2:1-18.

33. Alshawsh MA, Abdulla MA, Ismail S, Amin ZA. Hepatoprotective effects of Orthosiphon stamineus extract on thioacetamideinduced liver cirrhosis in rats. J Evidence-Based complimentary Altern Med 2011:1-6. http://dx.doi.org/10.1155/2011/ 103039

34. Han LK, Zheng YN, Yoshikawa M, Okuda H, Kimura Y. Antiobesity effects of chikusetsu saponins isolated from Panax japonicas rhizomes. BMC Complementary Altern Med 2005;6:5-9.

35. Yun SN, Moon SJ, Ko SK, Im Bo. Wild ginseng prevents the onset of high-fat diet induced hyperglycemia and obesity in ICR mice. Arch Pharm Res 2004;7:790-6.

36. Han LK, Zheng YN, Xu BJ, Kimura Y. Saponins from Platycodi radix ameliorate high fat diet-induced obesity in mice. J Nutr 2002;132:2241-5.

37. Yen TT, Allan JA, Pearson DV. Control of obesity in Avy/a mice by 5alpha-androstan-17-one. Experientia 1978;34:1542-3.

\section{How to cite this article}

Satish Khaserao, Rahul Somani. Evaluation of the anti-obesity activity of solasodine on high fat diet-induced obesity in the rat. Int J Pharm Pharm Sci 2017;9(3):23-29. 